\title{
Optimasi Pemasangan dan Kapasitas Kapasitor Shunt Pada Jaringan Distribusi Penjulang Menjangan
}

\author{
Chandra Wimar Tono Manurung ${ }^{1}$, I Wayan Sukerayasa ${ }^{2}$, Rukmi Sari Hartati ${ }^{3}$
}

\begin{abstract}
Optimization of installation and capacity of shunt capacitor on Menjangan feeder do for reactive power compensation in the primary distribution network so it could improve the power factor, reduce network losses and improve voltage profile on Menjangan feeder distribution network after the installation of a shunt capacitor. To obtain the optimum value of these parameters, using a process optimization tools Capacitor Sizing - Radial Network. From the results of simulation studies on the optimization of shunt capacitor Menjangan feeder, obtained optimum layout of shunt capacitors are place at a distance of $92,724 \mathrm{ft}(27.82 \mathrm{~km})$ from the source, or in single line diagram it place before Bus 28 (GR 122) in capacity of 1.800 kVAR. After using the installation of shunt capacitors, then experienced a power factor up from the initial conditions of simulation increase 0.79 to 0.91 , the voltage on Bus 91 (GR 115) increased by $16.4 \%$ (where the initial conditions of simulation $\mathbf{7 5 . 0 5 \%}$ increase to $91.42 \%$ ) and a decrease in losses of $29,3 \%$.
\end{abstract}

Intisari- Optimasi pemasangan dan kapasitas kapasitor shunt pada jaringan distribusi Penyulang Menjangan dilakukan untuk kompensasi daya reaktif pada beban sehingga dapat memperbaiki faktor daya, mengurangi rugi-rugi jaringan dan memperbaiki profil tegangan. Untuk mendapatkan nilai yang optimum dari parameter-parameter tersebut, menggunakan studi optimasi dengan tools Capacitor Sizing - Radial Network. Dari hasil studi simulasi optimasi kapasitor shunt pada Penyulang Menjangan, diperoleh letak optimum dari kapasitor shunt pada jarak $92.724 \mathrm{ft}(27,82 \mathrm{~km})$ dari sumber atau jika digambarkan pada diagram segaris berada sebelum Bus 28 (GR 122) dengan kapasitas 1.800 kVAR. Setelah dilakukan pemasangan kapasitor shunt tersebut, faktor daya naik dari kondisi awal simulasi 0,79 menjadi 0,91, tegangan pada Bus 91 (GR 115) mengalami peningkatan sebesar 16,4\% (dimana kondisi awal simulasi $75,05 \%$ naik menjadi $91,42 \%$ ) serta penurunan rugi-rugi jaringan sebesar $29,3 \%$.

Kata Kunci- daya reaktif, faktor daya, penurunan tegangan, rugi-rugi jaringan, optimasi.

\section{PENDAHULUAN}

Jaringan distribusi merupakan bagian dari sistem tenaga listrik yang berperan untuk menyalurkan energi tenaga listrik dari sumber daya listrik hingga ke konsumen. Kesehariannya konsumen di kawasan Jaringan distribusi Gilimanuk dan Singaraja menggunakan daya aktif tenaga listrik ke beban bersifat kapasitif maupun induktif, namun pada umumnya merupakan beban induktif seperti peralatan

\footnotetext{
${ }^{I}$ Mahasiswa Teknik Elektro, Universitas Udayana, Kampus Bukit Jimbaran, Badung, Bali, INDONESIA;

${ }^{2,3}$ Dosen Teknik Elektro, Universitas Udayana, Kampus

Bukit Jimbaran, Badung, Bali, INDONESIA;

e-mail: 'chandramanurung27@gmail.com,

${ }^{2}$ sukeravasa@unud.ac.id, ${ }^{3}$ rukmisari@unud.ac.id
}

listrik yang ada di perindustrian, pertokoan, perkantoran, fasilitas umum dan perumahan. Apabila beban reaktif induktif semakin besar akan berakibat terhadap faktor daya yang rendah, rugi-rugi jaringan serta menurunnya tegangan sehingga berdampak terhadap daya listrik yang diterima oleh konsumen lebih kecil daripada yang dikirimkan. Berdasarkan data dari PT.PLN Area Bali Utara menyatakan bahwa pada saat ini kondisi Penyulang Menjangan memiliki drop tegangan paling besar yang cukup tinggi yaitu sebesar 10,22\% (lebih dari batas tegangan minimum $-10 \%$ dari tegangan nominal [1]).

Apabila suatu jaringan tidak memiliki sumber daya reaktif kapasitif di daerah sekitar beban induktif dapat menurunkan faktor daya, memperbesar rugi-rugi jaringan serta memperbesar penurunan tegangan khususnya pada konsumen di ujung jaringan. Salah satu upaya yang dapat dilakukan untuk dapat mengurangi beban daya reaktif induktif adalah dengan penambahan sumber daya reaktif kapasitif melalui pemasangan kapasitor shunt. Kapasitor shunt berguna untuk menyuplai daya reaktif kapasitif yang dapat dimanfaatkan oleh beban reaktif induktif tersebut. Dengan demikian dapat menghasilkan faktor daya dengan ambang batas 0,9 [2], memperkecil rugi-rugi jaringan serta memperbaiki batas tegangan minimum sebesar $\quad-10 \%$ dari tegangan nominal [1].

Berikut beberapa uraian singkat dari refrensi penelitian yang menggunakan studi optimasi daya reaktif kapasitor shunt pada sistem distribusi primer $20 \mathrm{kV}$ yaitu menggunakan simulasi ETAP 7,5 [3] sehingga menghasilkan kenaikan tegangan pada ujung terima (kondisi awal $14,39 \mathrm{kV}$ menjadi $16,87 \mathrm{kV})$. Selanjutnya penelitian optimasi reaktif power dispatch (ORPD) menggunakan Real-Coded Genetic Algorithm (RGA) [4] dibandingkan dengan metode Genetic Algorithm (GA) standar memperlihatkan metode RGA memberikan solusi lebih efisien dibandingkan metode GA standar pada permasalahan ORPD.

Penelitian ini bertujuan untuk optimasi pemasangan dan kapasitas kapasitor shunt sehingga dapat memperbaiki faktor daya, mengurangi rugi-rugi jaringan, serta memperbaiki kualitas tegangan pada Penyulang Menjangan melalui studi optimasi dengan tools Capacitor Sizing - Radial Network.

\section{SISTEM JARINGAN DISTRIBUSI PENYULANG MENJANGAN}

Jaringan transmisi dan jaringan distribusi pada sistem tenaga listrik berfungsi sebagai sarana untuk menyalurkan tenaga listrik yang dihasilkan dari pusat pembangkit listrik ke pusat-pusat beban. Penyulang Menjangan berdasarkan tegangan kerjanya merupakan sistem jaringan distribusi primer radial $20 \mathrm{kV}$ (jaringan distribusi tegangan menengah), sedangkan tegangan kerja pada sistem jaringan distribusi sekunder adalah 220/380 V (jaringan distribusi tegangan 
menengah), seperti yang ditunjukkan pada Gambar 1 berikut.

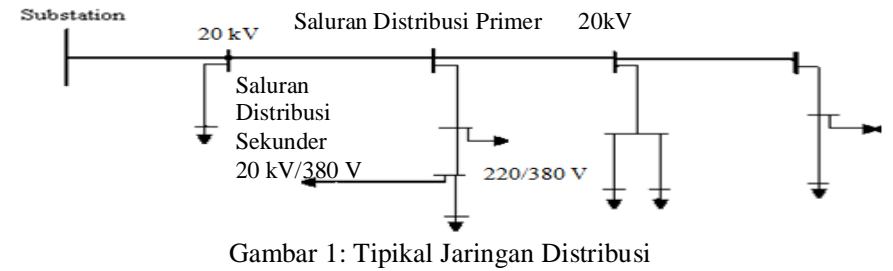

\section{KAPASITOR SHUNT}

Pembangkit daya reaktif pada perencanaan daya dan pensuplaiannya ke beban yang berjarak jauh adalah tidak ekonomis [6], tetapi dapat dengan mudah disediakan oleh kapasitor shunt yang ditempatkan pada pusat beban. Kapasitor shunt pada jaringan (Gambar 2) dapat menyuplai daya reaktif negatif yang dapat berpengaruh untuk mengurangi daya aliran reaktif di dalam jaringan sehingga dapat merubah karakteristik arus lagging dari beban reaktif induktif menjadi arus leading [5].

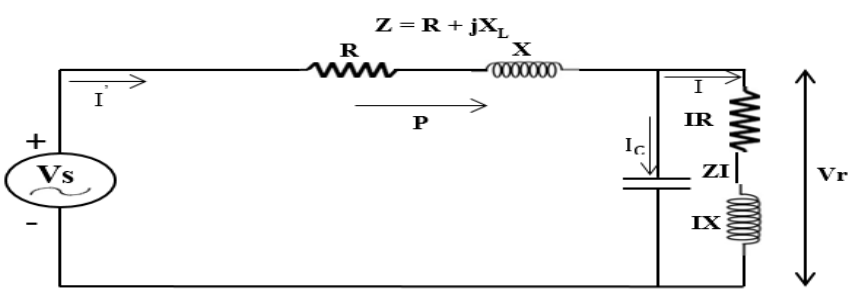

Gambar 2: Rangkaian Ekivalen Saluran Dengan Kapasitor Shunt

Maka, dengan dipasang kapasitor shunt pada saluran sisi penerima, dengan arus kapasitif $\left(\mathrm{I}_{\mathrm{C}}\right)$ dengan komponen arus reaktif yang leading $90^{\circ}$ terhadap tegangan, maka drop tegangan dapat diturunkan seperti gambar diagram fasor berikut :
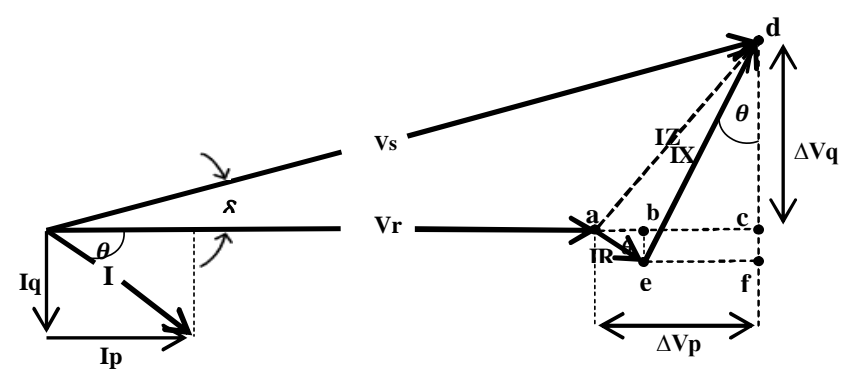

(a)
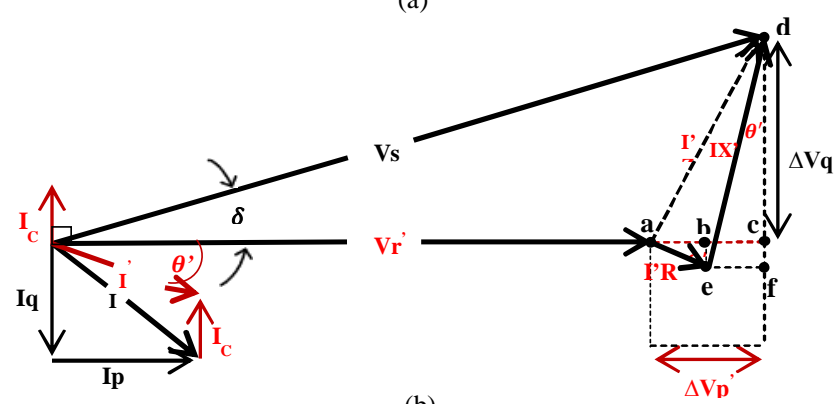

(b)

Gambar 3: Diagram Phasor (a). Saluran Tanpa Kapasitor Shunt (b). Saluran Dengan Kapasitor Shunt
Pada rangkaian ekivalen saluran tanpa menggunakan kapasitor shunt dengan faktor daya lagging memiliki persamaan drop tegangan berikut :

$\Delta \mathrm{V}_{\mathrm{p}}=\mathrm{IR} \cos \theta+\mathrm{IX} \sin \theta$

Maka setelah ditambahkan dengan dengan kapasitor shunt, nilai drop tegangan dapat dirumuskan sebagai berikut [7]:

$\Delta \mathrm{V}_{\mathrm{p}}{ }^{\prime}=\mathrm{IR} \cos \theta^{\prime}+\left(\mathrm{I}_{\mathrm{L}} \mathrm{X}_{\mathrm{L}}-\mathrm{I}_{\mathrm{C}} \mathrm{X}_{\mathrm{C}}\right) \sin \theta^{\prime}$

Atau persamaan dapat disederhanakan menjadi :

$$
\begin{aligned}
\Delta \mathrm{V}_{\mathrm{p}} & =\mathrm{IR} \cos \theta^{\prime}+\left(\mathrm{I}_{\mathrm{L}} \mathrm{X}_{\mathrm{L}}-\mathrm{I}_{\mathrm{C}} \mathrm{X}_{\mathrm{C}}\right) \sin \theta^{\prime} \\
& =\mathrm{IR} \cos \theta^{\prime}+\left(\mathrm{I}_{\mathrm{L}} \mathrm{X}_{\mathrm{L}} \sin \theta-\mathrm{I}_{\mathrm{C}} \mathrm{X}_{\mathrm{C}} \sin \theta^{\prime}\right) \\
& =\mathrm{R}\left(\frac{\mathrm{P}}{V_{r}^{\prime}}\right)+\mathrm{X}_{\mathrm{L}}\left(\frac{\mathrm{Q}_{\mathrm{L}}}{V_{r}^{\prime}}\right)-\mathrm{X}_{\mathrm{C}}\left(\frac{\mathrm{Q}_{\mathrm{C}}}{V_{r}^{\prime}}\right) \\
\Delta \mathrm{V}_{\mathrm{p}} & =\frac{\mathrm{P}}{V_{r}^{\prime}} \mathrm{R}+\frac{Q_{L} X_{L-} Q_{C} X_{C}}{V_{r}^{\prime}}
\end{aligned}
$$

dengan keterangan gambar dan persamaan :

$$
\begin{array}{ll}
\mathrm{V}_{\mathrm{s}}, & =\text { Tegangan dari sisi pengirim } \\
\mathrm{V}_{\mathrm{r}} & =\text { Tegangan pada sisi penerima } \\
\mathrm{R} & =\text { Resistansi saluran } \\
\mathrm{X} & =\text { Reaktansi saluran } \\
\mathrm{X}_{\mathrm{L}} & =\text { Reaktansi Induktif } \\
\mathrm{X}_{\mathrm{C}} & =\text { Reaktansi Capasitif } \\
\mathrm{I}_{\mathrm{p}} & =\text { Komponen arus aktif } \\
\mathrm{I}_{\mathrm{q}} & =\text { Komponen arus reaktif induktif } \\
\mathrm{IR} & =\text { Komponen real arus } \\
\mathrm{IX} & =\text { Reaktansi jaringan } \\
\mathrm{P} & =\text { Daya aktif yang dikirimkan ke beban } \\
\mathrm{Q} & =\text { Daya reaktif yang dikirimkan ke beban }
\end{array}
$$

Ketika dipasang kapasitor shunt, terjadi injeksi arus $\mathrm{I}_{\mathrm{C}}$ pada sistem sehingga faktor daya meningkat dan $\mathrm{I}_{\mathrm{L}}$ berkurang. Hal ini mengakibatkan drop tegangan berkurang $\left(\mathrm{I}_{\mathrm{L}} \mathrm{x} \mathrm{X}_{\mathrm{L}}\right)$ sehingga $V_{r}$ meningkat. Pernyataan ini seperti dijelaskan pada Gambar 3(a) sehingga dapat dituliskan persamaan sebagai berikut :

$$
\mathrm{V}_{\mathrm{r}}=\mathrm{V}_{\mathrm{s}}-(\mathrm{IR}+\mathrm{jIX})
$$

Kemudian melalui Gambar 3(b), dijelaskan bahwa :

$\mathrm{V}_{\mathrm{r}}{ }^{\prime}=\mathrm{V}_{\mathrm{s}}-\left(\mathrm{IR}+\mathrm{jI} \mathrm{I}_{\mathrm{L}} \mathrm{X}_{\mathrm{L}}-\mathrm{j} \mathrm{I}_{\mathrm{C}} \mathrm{X}_{\mathrm{C}}\right)$

Maka melalui kedua persamaan tersebut, diperoleh selisih drop tegangan sebagai berikut :

$$
\begin{aligned}
\Delta \mathrm{V}_{\mathrm{r}} & =\mathrm{V}_{\mathrm{r}}{ }^{\prime}-\mathrm{V}_{\mathrm{r}} \\
& =\left[\mathrm{V}_{\mathrm{s}}-\left(\mathrm{IR}+\mathrm{jI}_{\mathrm{L}} \mathrm{X}_{\mathrm{L}}-\mathrm{jI}_{\mathrm{C}} \mathrm{X}_{\mathrm{C}}\right)\right]-\left[\mathrm{V}_{\mathrm{s}}-\left(\mathrm{IR}+\mathrm{jI}_{\mathrm{L}} \mathrm{X}_{\mathrm{L}}\right)\right] \\
& =\mathrm{jI}_{\mathrm{C}} \mathrm{X}_{\mathrm{C}}
\end{aligned}
$$

Batas penurunan tegangan maksimum pada beban penuh yang diijinkan di beberapa titik sambung pada jaringan distribusi [1] adalah : Tegangan sistem distribusi harus dijaga pada batas-batas kondisi normal yaitu maksimal $+5 \%$ dan minimal $-10 \%$ dari tegangan nominal.

\section{KOREKSI FAKTOR DAYA}

Faktor daya atau sering disebut Power Factor ( $p f)$ atau cos phi merupakan rasio perbandingan antara daya aktif (P) terhadap daya semu/ daya total (S) yang dihasilkan oleh sumber atau cosinus sudut antara daya aktif dan daya semu/daya total (S) [8]. Pada sistem tenaga listrik AC (Alternaiting Current) atau arus bolak-balik terdapat tiga jenis daya, yaitu : daya aktif, daya reaktif dan daya semu. Daya semu (S) dengan satuan VA merupakan total daya yang dikirimkan dari sumber pembangkit tenaga listrik sehingga dapat dimnfaatkan sebagai daya aktif, namun sebaliknya 
semua daya semu yang disuplai dari sumber tidak dapat dimanfaatkan keseluruhannya dan menjadi daya reaktif pada jaringan saja. Hal ini dikarenakan oleh daya reaktif (VAR) pada jaringan menghasilkan fluks medan magnetik sehingga timbul magnetisasi dan daya ini akan dikirimkan ke sumber akibat efek induksi elektromagnetik tersebut sehingga daya ini menjadi beban pada sistem tenaga listrik. Berikut ini kita dapat dilihat diagram vektor hubungan antara daya aktif dan daya reaktif pada Gambar 4 :

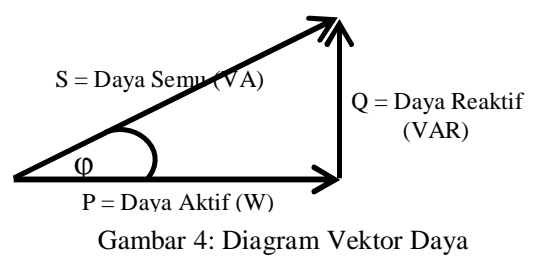

Dari Gambar 4, dinyatakan bahwa daya semu (S) adalah :

$$
\begin{aligned}
& \mathrm{S}=\sqrt{P^{2}+Q^{2}} \\
& \mathrm{P}=\mathrm{V} I \operatorname{Cos} \varphi \quad \text { (Watt) } \\
& \mathrm{Q}=\mathrm{V} \text { I Sin } \varphi \text { (VAR) } \\
& \mathrm{S}=\mathrm{V} \mathrm{I} \quad \text { (VA) }
\end{aligned}
$$

Faktor daya $(\operatorname{Cos} \varphi)$ dapat dinyatakan sebagai berikut :

$$
\text { Faktor Daya } \begin{aligned}
(P F) & =\frac{\text { Daya Aktif }(P)}{\text { Daya Semu }(S)} \\
& =\frac{W}{V A} \\
& =\frac{V I \operatorname{Cos} \varphi}{V I}=\operatorname{Cos} \varphi
\end{aligned}
$$

Ketika kapasitor shunt ditambahkan ke beban, maka faktor daya dapat ditingkatkan dari $\cos \varphi_{1} \operatorname{ke} \cos \varphi_{2}$, sehingga tegangan terima bus juga meningkat. Untuk memperoleh hasil optimal, akan kekurangan daya reaktif oleh beban dapat dipenuhi dengan pemasangan kapasitor shunt sehingga diperoleh faktor daya pada bus yang mendekati 1 [9].

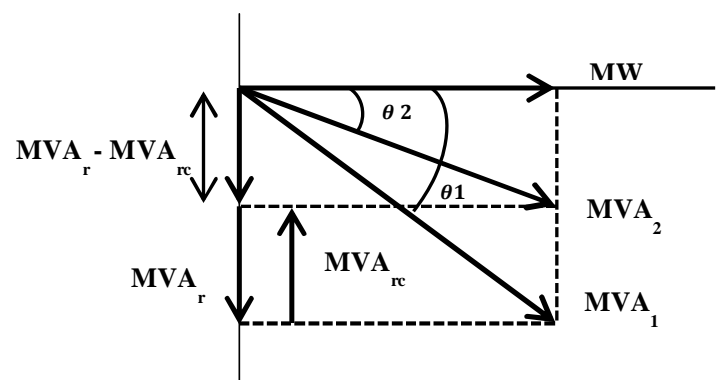

Gambar 5: Perbandinga besar daya semu yang dibutuhkan sebelum dan sesudah ditambahkan kapasitor shunt

$$
\begin{array}{cl}
\mathrm{MVA}_{1}=\mathrm{MW} & +\mathrm{jMVA} \\
\mathrm{MVA}_{2}=\mathrm{MW} & +\mathrm{jMVA} \mathrm{A}_{\mathrm{r}}-\mathrm{jVA}_{\mathrm{rc}} \\
\Delta \mathrm{MVA}=\mathrm{MVA}_{2}-\mathrm{MVA}_{1}=\mathrm{jVAR}_{\mathrm{c}} & \\
\text { dengan : } & =\text { Daya semu/nyata } \\
\mathrm{MVA} & =\text { Daya aktif } \\
\mathrm{MW} & =\text { Daya reaktif } \\
\mathrm{MVA}_{\mathrm{r}} & =\text { Injeksi daya reaktif dari kapasitor. }
\end{array}
$$

Chandra Wimartono Manurung: Optimaasi Pemasangan dan Kapasitas... $\quad$ p-ISSN:1693 - 2951; e-ISSN: 2503-2372

\section{OPTIMASI PEMASANGAN DAN KAPASITAS KAPASITOR SHUNT DENGAN TOOLS CAPACITOR SIZING-RADIAL NETWORK}

Pada penelitian ini menggunakan tools Capacitor Sizing Radial Network sebagai studi optimasi penentuan pemasangan dan kapasitas kapasitor shunt untuk memperbaiki faktor daya, mengurangi rugi-rugi daya dan memperbaiki tegangan pada sistem distribusi.

Pada tahap optimasi terdapat parameter dan batasan parameter daya yang akan dicari, diantaranya parameter yang dicari hanya 2 yaitu lokasi dan nilai optimal kapasitor shunt yang akan dipasang [9]. Kemudian nilai ukuran kapasitas kapasitor shunt berupa bilangan integer kelipatan 10 sesuai dengan kapasitor yang digunakan yaitu sebesar $10 \mathrm{MVAr}$. Nilai kapasitor ini berisikan nilai dengan range diantara 0 hingga 400 MVAr. Kemudian dalam optimasi pemasangan kapasitor besarnya tegangan dipakai sebagai fungsi kendala dalam perhitungan sehingga berada pada batas toleransi yang diijinkan [5], yaitu :

$\mathrm{V}^{\mathrm{min}} \leq \mathrm{V}_{\mathrm{i}} \leq \mathrm{V}^{\text {maks }}$

Serta faktor daya, dengan batasan yang diijinkan yaitu :

$\mathrm{PF}_{\text {min }} \leq \mathrm{PF} \leq \mathrm{PF}_{\text {maks }}$, untuk $\mathrm{i}=1, \ldots . \mathrm{n}$ dengan :

$$
\begin{array}{llll}
\mathrm{i} & =\text { nomor bus } & \mathrm{PF} & =\text { power factor }(\cos \theta) \\
\mathrm{V}^{\text {min }} & =0,90 \% & & \mathrm{PF}_{\text {min }}=0,85 \\
\mathrm{~V}^{\text {maks }} & =1,05 \% & & \mathrm{PF}_{\text {maks }}=0,9
\end{array}
$$

Penelitian ini dilakukan di laboratorium Riset Manajemen Energi Listrik, Jurusan Teknik Elektro dan Komputer, Fakultas Teknik, Universitas Udayana, Jimbaran. Jadwal penelitian dimulai dari bulan Mei 2016 hingga Juli 2016. Penelitian ini dilakukan dengan pengumpulan data langsung dari PT.PLN (PERSERO) Distribusi Bali Area Bali Utara Rayon Gilimanuk. Analisis data dalam penelitian ini dilakukan dalam beberapa tahapan diantaranya :

1. Pengumpulan data berupa single line diagram, data kapasitas transformator, data pembebanan masing-masing transformator, data impedansi saluran distribusi serta panjang dan jenis penghantar pada Penyulang Menjangan.

2. Menggambar single line diagram Penyulang Menjangan serta memasukkan data-data sistem jaringan yang diperloeh serta beberapa data ini [10], seperti :

- Cost of demand power (kVA/year) at the substation Cost of Substation merupakan tarif harga pemakaian listrik dari gardu induk (GI) ke masing - masing beban yang digolongkan atas beberapa kriteria golongan tarif. Pada penentuan tariff ini, digunakan persamaan berikut :

Total Harga $=$ Beban Jaringan $(\mathrm{kW}) \times$ Harga Tarif (17)

- Cost of energy losses $(\$ / \mathrm{kWh})$

Energy Lost Cost merupakan harga jual tenaga listrik perharinya berdasarkan waktu penggunaan dari beban atau konsumen.

- Cost of capacitor annual investment ( $\$ / k V A R / y e a r)$ Cost of Capacitor merupakan biaya investasi berdasarkan harga saat ini yang digunakan untuk p-ISSN:1693 - 2951; e-ISSN: 2503-2372

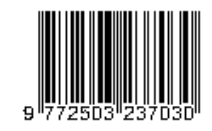


pemasangan kapasitor shunt pada jaringan distribusi Penyulang Menjangan.

- Load demand factor

Load Demand Factor merupakan perbandingan antara kebutuhan maksimum (beban puncak) terhadap total daya tersambung, seperti persamaan berikut :

Load Demand Faktor $=\frac{\text { Kebutuhan Maksimum }(\mathrm{kVA})}{\text { Jumlah Daya Tersambung }(\mathrm{kVA})}$

- Low load level percentage

- Permitted voltage increase in \% at the low load level

- The maximum iteration number of the low load flow calculation

- The tolerance of the load flow calculations

- The "from" bus and "to" bus ID code for the primary feeder along which the capacitor bank will be place

- Capacitor standar size

3. Menghitung aliran daya pada jaringan dengan metode Newton-Raphson kemudian melakukan studi optimasi aliran daya dengan tools Capacitor Sizing - Radial Network.

4. Menganalisa hasil perhitungan berupa rugi - rugi daya dan power faktor saat kondisi sebelum dan sesudah diinjeksikan kapasitor shunt, mengamati letak dan nilai kapasitor yang diinjeksikan pada sistem jaringan Penyulang Menjangan serta menganalisa besarnya economic benefits yang diperoleh melalui injeksi kapasitor pada sistem jaringan tersebut.

\section{SIMULASI DAN PEMBAHASAN}

\section{A. Data Masukan Jaringan Penyulang Menjangan}

Penyulang Menjangan merupakan penyulang dengan konfigurasi tipe radial $20 \mathrm{kV}$ dengan sumber energi listrik yang disuplai dari Gardu Induk Trafo II 10 MVA Gilimanuk. Berikut Detail dan karakteristik beban pada Penyulang Menjangan :

Base MVA

Panjang Jaringan

Jumlah Transformator

: 10 MVA

Jumlah Pelanggan

: 64,373 kms

: 69 Unit

Total Daya Transformator

: 9.218 Pelanggan

: $9.360 \mathrm{kVA}$

: $3.665,91 \mathrm{kVA}$

Beban Jaringan

Berikut nilai dari resistansi dan reaktansi dari data-data penghantar pada Penyulang Menjangan [11] :

TABEL I

Nilai Impedansi Penyulang Menjangan

\begin{tabular}{|c|c|c|c|c|c|}
\hline \multirow{2}{*}{ No. } & \multirow{2}{*}{ Jenis Penghantar } & \multicolumn{2}{|c|}{$\mathbf{Z 1} / \mathbf{k m}$} & \multicolumn{2}{|c|}{$\mathbf{Z 0} / \mathbf{~ k m}$} \\
\cline { 3 - 6 } & $\mathbf{R}$ & $\mathbf{j X}$ & $\mathbf{R}$ & $\mathbf{j X}$ \\
\hline & $\begin{array}{c}\text { Kabel Tanah (NFA2XSEY- } \\
\text { T) } 150 \mathrm{~mm}^{2}\end{array}$ & 0,206 & 0,104 & 0,356 & 0,312 \\
\hline 2 & MV-TIC $150 \mathrm{~mm}^{2}$ & 0,216 & 0,330 & 0,363 & 1,618 \\
\hline 3 & AAAC $150 \mathrm{~mm}^{2}$ & 0,216 & 0,330 & 0,363 & 1,618 \\
\hline 4 & AAAC $95 \mathrm{~mm}^{2}$ & 0,309 & 0,345 & 0,487 & 1,632 \\
\hline 5 & AAACS $150 \mathrm{~mm}^{2}$ & 0,216 & 0,330 & 0,363 & 1,618 \\
\hline
\end{tabular}

Kemudian selain data diatas yang akan diinput dalam pengolahan studi optimasinya, berikut ini juga diperlukan data-data yang menjadi parameter terhadap economic benefits yang akan diperoleh melalui perhitungan dan asumsi sebagai berikut :

1. Cost of Substation $k V A(\$ / k V A /$ year $)$
Berdasarkan pada Penyesuaian Tarif Tenaga Listrik (Tariff Adjustment) bulan Agustus 2016 PT. PLN (Persero) Distribusi Bali bahwa biaya pemakaian kapasitas energi listrik (Rp/kWh) terdapat 12 kriteria golongan tariff dengan nilai rata-rata sebesar Rp.1.241,007/kWh. Dengan melakukan perhitungan besarnya daya pembebanan pada Penyulang Menjangan, maka Cost of Substation berdasarkan persamaan (17) adalah :

Total Beban Jaringan $=3.665,91 \mathrm{kVA}$

Total Harga

$$
\begin{aligned}
& =[3.665,91(0,9)] \times \text { Rp. } 1.241,007 \\
& =\text { Rp. } 4.094 .477,97 / \mathrm{kW} \\
& =\text { Rp. } 4.549 .419,97 / \mathrm{kVA}
\end{aligned}
$$

Dengan konversi besarnya nilai dolar saat ini $1 \$=13.200$, maka cost of substation sebesar \$344,653 jika dibulatkan menjadi \$ 345/kVA/year.

\section{Energy Lost Cost $(\$ / \mathrm{kWh})$}

Berdasarkan Tarif Tenaga Listrik dari P2B ke sistem distribusi tahun 2016 PT. PLN (Persero) Distribusi Bali harga jualnya terdiri dari 3 kriteria dengan nilai rata-rata sebesar Rp. $740,33 / \mathrm{kWh}$ jika dikonversikan ke dalam satuan dolar (\$) dengan update terbaru agustus untuk nilai per dolarnya sebesar Rp. 13.200 maka menjadi \$ 0,056/kWh.

3. Capacitor Investment Cost ( $\$ / k V A R / y e a r)$

Berdasarkan data yang saya peroleh bahwa sebuah kapasitor dengan kapasitas $600 \mathrm{kVAR}$ dengan perkiraan biaya perawatan hingga 15 tahun memiliki harga sebesar Rp. 95 juta rupiah, yang berarti setiap kVAR nya sebesar Rp. 158.333,33. Dengan umur pakai selama 15 tahun, maka besar dana yang harus diinvestasikan pertahunnya sebesar Rp.10.555,55/tahun/kVAR jika dikonversikan kedalam satuan dolar (\$) dengan nilai perdolarnya sebesar Rp. 13.200 menjadi $\$ 0,8$ /year/kVAR.

4. Load Demand Factor

Berdasarkan persamaan (18), diperoleh nilai load demand faktorsebagai berikut:

$$
\begin{aligned}
\text { Load Demand Faktor } & =\frac{3.665,91 \mathrm{kVA}}{9.360 \mathrm{kVA}} \\
& =\mathbf{0 , 3 9}
\end{aligned}
$$

5. Low Load Level Percent

Pada kesempatan ini, nilai Low load level percent diasumsikan dengan nilai sebesar $\mathbf{6 0 \%}$.

6. Permitted Voltage Up \% at Low Load Level

Berdasarkan standart bahwa batas tegangan minimum yang diijinkan pada tegangan menengah sebesar $-10 \%$ dari tegangan nominal [1].

7. The "from" bus and "to" bus ID code for the primary feeder along which the capacitor bank will be place

Tahap ini yaitu menetukan penempatan kapasitor yang akan dipasang yang dimulai dari sumber pembangkitan Gardu Induk Gilimanuk Trafo II hingga ujung jaringan distribusi. 


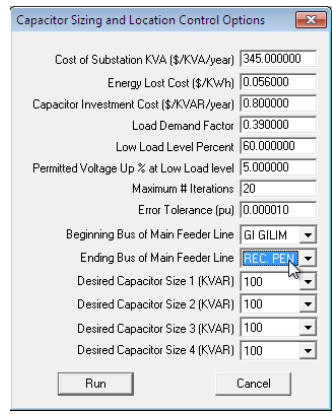

Gambar 6: Data masukan yang tampak pada tampilan form untuk perhitungan economic benefits

\section{B. Hasil Simulasi Optimasi Kapasitor Shunt Pada Penyulang Menjangan}

Simulasi dilakukan dengan 3 tahapan,yaitu tahap awal adalah menghitung kondisi awal aliran daya pada penyulang dengan menggunakan metode Newton-Raphson kemudian melakukan studi optimasi kapasitor shunt dengan tools Capasitor Sizing - Radial Network untuk menentukan letak dan nilai optimal dari kapasitor shunt yang akan diinjeksikan pada penyulang, setelah itu melakukan perhitungan aliran daya kembali setelah diinjeksikan kapasitor shunt sesuai dengan lokasi dan nilai yang telah diperoleh melaui studi optimasi sebelumnya.

Capacitor size: $1800.00 \mathrm{KVAR}$ 300.00 KVAR X 6

Capacitor location (from source substation):

$92724 \mathrm{Ft} 92.724 \mathrm{KFt}$

Substation power output, power factor and network loss

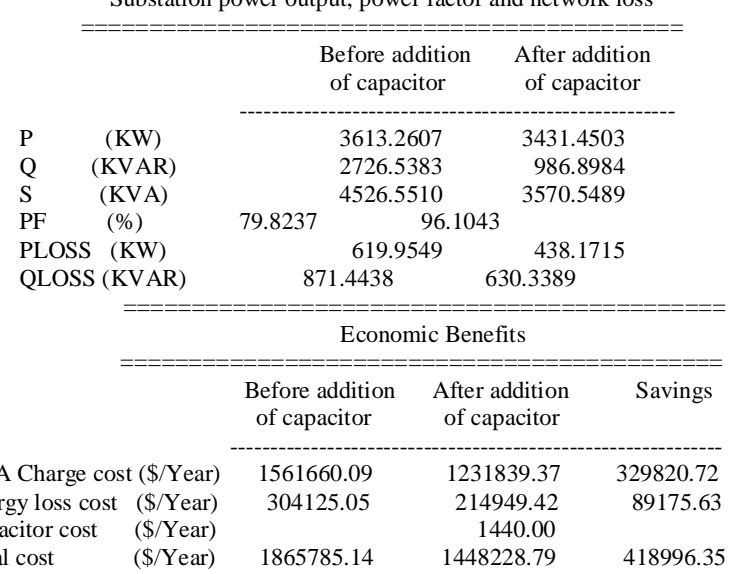

Kemudian berikut hasil aliran daya secara umum setelah hasil studi optimasi lokasi dan kapasitas diperoleh, dengan tools Capacitor Sizing - Radial Network:

\begin{tabular}{|c|c|c|c|c|}
\hline & Summary o & otal Generat & nd Deman & \\
\hline & $\mathrm{P}(\mathrm{MW})$ & Q(MVAR) & S(MVA) & $\mathrm{PF}$ \\
\hline Swing Bus(es) & : 3,433 & $-1,492$ & 3,744 & 0.91 \\
\hline Generators & $: 0.000$ & 0.000 & 0.000 & 0.00 \\
\hline Total Load & : 2.993 & -2.111 & 3.663 & 0.81 \\
\hline Total Loss & : 0.440 & 0.618 & & \\
\hline Mismatch & $: 0,000$ & 0,000 & & \\
\hline
\end{tabular}

Berikut ini dapat dilihat perubahan aliran daya pada Penyulang Menjangan disaat kondisi sebelum dan setelah ditambahkan kapasitor shunt :

Chandra Wimartono Manurung: Optimaasi Pemasangan dan Kapasitas...
TABEL II

Perbandingan aliran daya saat kondisi sebelum dan sesudah ditambahkan kapasitor shunt

\begin{tabular}{|c|c|c|c|c|c|c|}
\hline \multirow[b]{2}{*}{ Bus } & \multicolumn{2}{|c|}{ Tegangan $(\%)$} & \multicolumn{2}{|c|}{ Pembangkitan } & \multicolumn{2}{|c|}{ Konsumsi } \\
\hline & Sebelum & Sesudah & $\begin{array}{c}\mathbf{P} \\
\text { (MW) }\end{array}$ & $\begin{array}{c}\mathbf{Q} \\
\text { (MVAr) }\end{array}$ & $\begin{array}{c}\mathbf{P} \\
(\mathbf{M W})\end{array}$ & $\begin{array}{c}\mathbf{Q} \\
\text { (MVAr) }\end{array}$ \\
\hline Bus 1 & 100,00 & 99,96 & 3,61 & 2,74 & 0,03 & 0,02 \\
\hline Bus 2 & 97,46 & 98,91 & 0 & 0 & 0,06 & 0,04 \\
\hline Bus 3 & 93,72 & 98,56 & 0 & 0 & 0,03 & 0,02 \\
\hline Bus 4 & 89,62 & 98,25 & 0 & 0 & 0,01 & 0,01 \\
\hline Bus 6 & 88,01 & 98,20 & 0 & 0 & 0,04 & 0,02 \\
\hline Bus 7 & 88,00 & 98,19 & 0 & 0 & 0,01 & 0,01 \\
\hline Bus 8 & 86,38 & 98,04 & 0 & 0 & 0,04 & 0,02 \\
\hline Bus 9 & 85,90 & 97,93 & 0 & 0 & 0,02 & 0,01 \\
\hline Bus 11 & 85,82 & 97,91 & 0 & 0 & 0,04 & 0,02 \\
\hline Bus 13 & 84,79 & 97,95 & 0 & 0 & 0,03 & 0,02 \\
\hline Bus 15 & 84,75 & 97,92 & 0 & 0 & 0,03 & 0,02 \\
\hline Bus 16 & 84,73 & 97,91 & 0 & 0 & 0,03 & 0,02 \\
\hline Bus 17 & 84,69 & 97,87 & 0 & 0 & 0,07 & 0,04 \\
\hline Bus 18 & 84,76 & 97,96 & 0 & 0 & 0,10 & 0,06 \\
\hline Bus 20 & 84,53 & 97,99 & 0 & 0 & 0,01 & 0,00 \\
\hline Bus 21 & 84,25 & 97,99 & 0 & 0 & 0,06 & 0,04 \\
\hline Bus 22 & 84,08 & 98,02 & 0 & 0 & 0,02 & 0,01 \\
\hline Bus 24 & 83,96 & 98,02 & 0 & 0 & 0,02 & 0,01 \\
\hline Bus 25 & 83,80 & 98,04 & 0 & 0 & 0,03 & 0,02 \\
\hline Bus 27 & 83,29 & 98,13 & 0 & 0 & 0,03 & 0,02 \\
\hline Bus 28 & 83,23 & 98,06 & 0 & 0 & 0,02 & 0,01 \\
\hline Bus 30 & 83,11 & 97,96 & 0 & 0 & 0,02 & 0,01 \\
\hline Bus 31 & 83,01 & 97,88 & 0 & 0 & 0,05 & 0,03 \\
\hline Bus 32 & 82,89 & 97,78 & 0 & 0 & 0,04 & 0,03 \\
\hline Bus 35 & 82,20 & 97,23 & 0 & 0 & 0,01 & 0,01 \\
\hline Bus 38 & 82,19 & 97,21 & 0 & 0 & 0,04 & 0,03 \\
\hline Bus 39 & 82,17 & 97,19 & 0 & 0 & 0,05 & 0,03 \\
\hline Bus 40 & 82,15 & 97,18 & 0 & 0 & 0,05 & 0,03 \\
\hline Bus 41 & 82,14 & 97,17 & 0 & 0 & 0,02 & 0,01 \\
\hline Bus 42 & 82,06 & 97,11 & 0 & 0 & 0,06 & 0,04 \\
\hline Bus 43 & 81,79 & 96,89 & 0 & 0 & 0,02 & 0,02 \\
\hline Bus 45 & 81,41 & 96,58 & 0 & 0 & 0,02 & 0,02 \\
\hline Bus 46 & 81,38 & 96,56 & 0 & 0 & 0,05 & 0,03 \\
\hline Bus 47 & 81,12 & 96,34 & 0 & 0 & 0,03 & 0,02 \\
\hline Bus 48 & 80,25 & 95,63 & 0 & 0 & 0,02 & 0,01 \\
\hline Bus 50 & 79,88 & 95,34 & 0 & 0 & 0,01 & 0,01 \\
\hline Bus 51 & 79,88 & 95,18 & 0 & 0 & 0,08 & 0,05 \\
\hline Bus 53 & 79,41 & 94,95 & 0 & 0 & 0,08 & 0,05 \\
\hline Bus 54 & 79,29 & 94,86 & 0 & 0 & 0,08 & 0,05 \\
\hline Bus 55 & 79,26 & 94,83 & 0 & 0 & 0,02 & 0,01 \\
\hline Bus 56 & 79,20 & 94,78 & 0 & 0 & 0,02 & 0,01 \\
\hline Bus 57 & 79,04 & 94,65 & 0 & 0 & 0,02 & 0,01 \\
\hline Bus 58 & 78,93 & 94,56 & 0 & 0 & 0,01 & 0,01 \\
\hline Bus 59 & 78,83 & 94,48 & 0 & 0 & 0,08 & 0,05 \\
\hline Bus 60 & 78,78 & 94,44 & 0 & 0 & 0,04 & 0,03 \\
\hline Bus 61 & 78,72 & 94,40 & 0 & 0 & 0,04 & 0,03 \\
\hline Bus 63 & 78,41 & 94,14 & 0 & 0 & 0,01 & 0,00 \\
\hline Bus 64 & 78,18 & 93,95 & 0 & 0 & 0,17 & 0,12 \\
\hline Bus 65 & 77,55 & 93,44 & 0 & 0 & 0,03 & 0,02 \\
\hline Bus 66 & 76,93 & 92,94 & 0 & 0 & 0,03 & 0,02 \\
\hline Bus 68 & 76,69 & 92,75 & 0 & 0 & 0,01 & 0,01 \\
\hline Bus 70 & 76,67 & 92,73 & 0 & 0 & 0,02 & 0,02 \\
\hline Bus 71 & 76,46 & 92,56 & 0 & 0 & 0,06 & 0,04 \\
\hline Bus 72 & 76,34 & 92,46 & 0 & 0 & 0,10 & 0,07 \\
\hline Bus 73 & 76,25 & 92,39 & 0 & 0 & 0,05 & 0,03 \\
\hline Bus 74 & 76,14 & 92,30 & 0 & 0 & 0,01 & 0,01 \\
\hline Bus 75 & 76,00 & 92,19 & 0 & 0 & 0,03 & 0,02 \\
\hline Bus 76 & 75,95 & 92,14 & 0 & 0 & 0,08 & 0,05 \\
\hline Bus 77 & 75,35 & 91,66 & 0 & 0 & 0,07 & 0,04 \\
\hline Bus 79 & 75,32 & 91,63 & 0 & 0 & 0,08 & 0,05 \\
\hline Bus 80 & 75,31 & 91,62 & 0 & 0 & 0,08 & 0,05 \\
\hline Bus 81 & 75,28 & 91,60 & 0 & 0 & 0,06 & 0,04 \\
\hline Bus 82 & 75,21 & 91,55 & 0 & 0 & 0,04 & 0,02 \\
\hline Bus 83 & 75,13 & 91,48 & 0 & 0 & 0,13 & 0,09 \\
\hline Bus 85 & 75,10 & 91,46 & 0 & 0 & 0,02 & 0,01 \\
\hline Bus 86 & 75,10 & 91,46 & 0 & 0 & 0,07 & 0,05 \\
\hline Bus 88 & 75,06 & 91,42 & 0 & 0 & 0,10 & 0,07 \\
\hline Bus 89 & 75,06 & 91,42 & 0 & 0 & 0,04 & 0,03 \\
\hline Bus 91 & 75,05 & 91,42 & 0 & 0 & 0,02 & 0,01 \\
\hline
\end{tabular}

p-ISSN:1693 - 2951; e-ISSN: 2503-2372 
Berdasarkan hasil program optimasi di atas diperoleh bahwa terjadi penurunan nilai $\mathrm{P}, \mathrm{Q}, \mathrm{S}, \mathrm{P}_{\text {loss }}$ dan $\mathrm{Q}_{\text {loss }}$ dengan menginjeksikan kapasitor shunt sebesar $1.800 \mathrm{kVAR}$ pada Penyulang Menjangan sehingga meningkatkan nilai faktor daya menjadi 0,96 (ambang batas faktor daya sebesar 0,9 [2]) sebelumnya 0,79 serta penurunan rugi-rugi jaringan 29,3\% (kondisi awal 619,95 kVA menjadi 438,17 kVA). Kemudian dapat dilihat bahwa posisi kapasitor yang paling optimum berada pada jarak $92.724 \mathrm{ft}(27,82 \mathrm{~km})$ dari sumber atau jika digambarkan pada diagram segaris berada sebelum Bus 28 (GR 122). Pada hasil kalkulasi optimasi ini juga diketahui besarnya penghematan yang dapat dilakukan sebesar $\$$ 418.996,35/year jika dikonversikan ke dalam rupiah ( $1 \$=\mathrm{Rp}$. 13.200) menjadi Rp. 5.530.751.820 (5,5 milliar rupiah) pertahun atau sekitar Rp. 460.895 .985 (460 juta rupiah) setiap bulannya.

Berikut ini digambarkan kedalam bentuk grafik perubahan tegangan antara sebelum dan sesudah ditambahkan kapasitor shunt pada penyulang Menjangan :

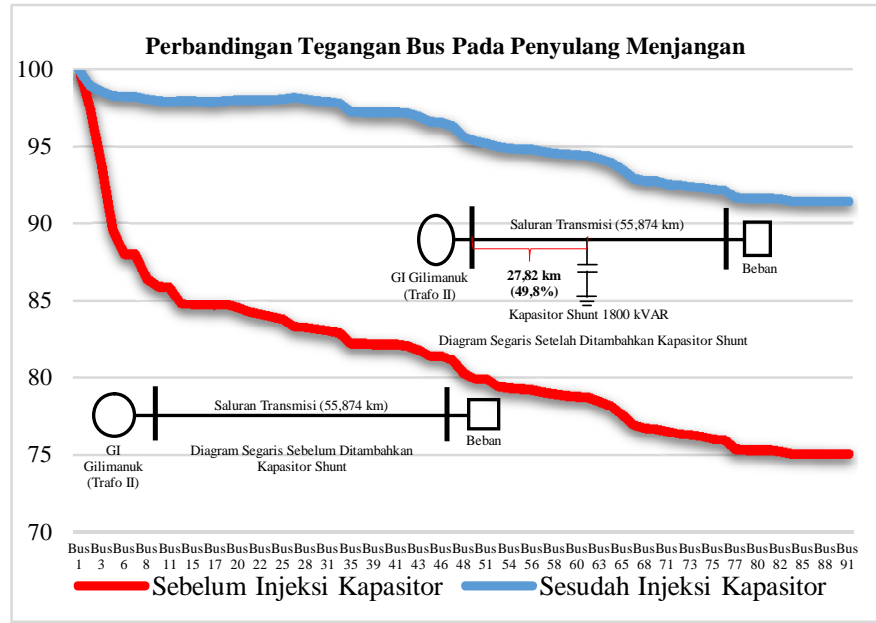

Gambar 7: Grafik Perbandingan Tegangan Bus Sebelum dan Sesudah Ditambahkan Kapasitor Shunt Pada Penyulang Menjangan

Melalui data pada tabel II diatas dapat dilihat bahwa hasil running studi optimasi Capacitor Sizing - Radial Network, terdapat peningkatan persentase tegangan secara signifikan pada masing-masing sistem bus dari sebelum diinjeksinya dengan sesudah diinjeksinya kapasitor shunt, serta sudah sesuai dengan batas tegangan minimum -10\% [1] dari tegangan nominal, seperti yang terjadi pada Bus 91 (GR 115) yang merupakan ujung Penyulang Menjangan pada awal simulasi memiliki persentase tegangan $75,05 \%$ mengalami peningkatan menjadi $91,42 \%$.

Seperti yang dijelaskan pada Gambar 3(b), bahwa ketika sistem jaringan ditambahkan kapasitor shunt, terjadi injeksi arus kapasitif $\left(\mathrm{I}_{\mathrm{C}}\right)$ sehingga faktor daya meningkat dan arus beban $\left(I_{L}\right)$ berkurang. Hal ini mengakibatkan drop tegangan berkurang sehingga tegangan terima $\left(\mathrm{V}_{\mathrm{r}}\right)$ pada masing masing bus mengalami peningkatan.

\section{KESIMPULAN}

Kesimpulan yang dapat diambil dari hasil pembahasan pada bab sebelumnya adalah sebagai berikut :

1. Melalui simulasi optimasi kapasitor shunt pada jaringan distribusi Penyulang Menjangan didapatkan lokasi dan kapasitansi kapasitor shunt yang paling optimum adalah berjarak $92.724 \mathrm{ft}(27,82 \mathrm{~km})$ dari sumber atau jika digambarkan pada diagram segaris berada sebelum Bus 28 (GR 122) dengan kapasitas sebesar 1.800 kVAR. Kenaikan nilai faktor daya setelah diinjeksi kapasitor shunt mencapai 0,91 yang sebelumnya 0,79 .

2. Proses simulasi Optimasi kapasitor shunt pada jaringan distribusi Penyulang Menjangan dapat mereduksi rugi rugi daya sebesar 29,3\% (kondisi awal 619,95 kVA menjadi 438,17 kVA), sehingga kapasitas pembebanan sistem dapat ditingkatkan.

3. Proses optimasi kapasitor shunt juga berpengaruh terhadap perbaikan tegangan, dimana sebelumnya pada Bus 91 (GR 115) mengalami persentase tegangan sebesar $75,05 \%$ naik menjadi $91,42 \%$.

4. Pada hasil simulasi optimasi juga dapat mengetahui besarnya penghematan biaya hingga $\$ 418.996,35 /$ year (Rp. 5.530.751.820/tahun) atau sekitar Rp. 460.895.985 (sekitar 460 juta rupiah) setiap bulannya.

\section{REFERENSI}

[1] ESDM Nomor 04 Tahun 2009. "Peraturan Menteri Energi Dan Sumber Daya Mineral - Aturan Distribusi Tenaga Listrik"

[2] SPLN No. 01727/532/DDPKP/2005. Jakarta : "Ambang batas faktor daya pada Jaringan, PLN 2005".

[3] Erhaneli, Ramadonal. 1 Januari 2015. "Optimasi Pemasangan Kapasitor Dalam Perbaikan Faktor Daya Dan Drop Tegangan Pada Sistem $20 \mathrm{kV}$ Menggunakan Simulasi ETAP 7.5”. Jurnal Teknik Elektro Institut Teknologi Padang, Vol. 4. No. 1.

[4] Setiawan, Widyadi; Utama, Satriya. 2011. "Optimasi Reaktif Power Dispatch Menggunakan Real-Coded Genetic Algorithm (RGA)". Majalah Ilmiah Teknologi Elektro Universitas Udayana, Vol 10. No 1. Januari - Juni.

[5] Hartati, Rukmi S. DKK. 2007. “ Penerapan Theorema Fuzzy Untuk Menentukan Lokasi Pemasangan dan Kapasitas Kapasitor Pada Saluran Distribusi Primer". Majalah Ilmiah Teknologi Elektro Universitas Udayana, Vol 6. No 2. Juli - Desember.

[6] Baran, M.E. and Wu, F.F1989. "Optimal Capasitor Placement On Radial Distribution Systems". IEEE Transactions on Power Delivery, Vol. 4. No. 1.

[7] Wijanarko, Eko. 2011. "Optimasi Penempatan Kapasitor Shunt Untuk Perbaikan Daya Reaktif Pada Penyulang Distribusi Primer Radial Dengan Algoritma Genetika" (Jurnal). Universitas Diponegoro, L2F 002576.

[8] Tampubolon, David; Sjani, Masykur. 2014. "Optimalisasi Penggunaan Kapasitor Bank Pada Jaringan 20 KV dengan Simulasi ETAP (Studi Kasus pada Feeder Srikandi di PLN Rayon Pangkalan Balai, Sumatera Selatan". Singuda Ensikom - USU, Vol. 9. No. 2/November.

[9] Robandi, imam. 2006. "Desain Sistem Tenaga Modern". Yogyakarta : ANDI.

[10] EDSA®. 2001. "Electrical Distribution And Transmission System Analyses And Design Programs". San Diego : EDSA MICO CORPORATION.

[11] SPLN 64, 1985. Jakarta : "Petunjuk Pemilihan dan Penggunaan Pelebur Pada Sistem Distribusi Tegangan Menengah, PLN 1985". 